\title{
FAKTOR-FAKTOR YANG MEMPENGARUHI REALISASI PENERIMAAN PAJAK BUMI DAN BANGUNAN SEKTOR PEDESAAN DAN PERKOTAAN DI KABUPATEN BANGKA TENGAH
}

\author{
MEIRISKA FEBRIANTI
}

\author{
STIE Trisakti \\ aurellya_mf@yahoo.com
}

\begin{abstract}
The purpose of this research is to examine the effect of the taxpayers, the population, the area, the amount of the building, gross regional domestic product towards the realization of property tax in Central Bangka District. The object of this research is property tax's revenues received by the municipal governments of Central Bangka District. The population in this research is all of the villages in Central Bangka District which are 67 Villages. Samples that used in the research are 250 samples, from 50 Villages from 2010 to 2014. The data used in this research is secondary data. The result of this research are the number of taxpayers have an effect on realization of property tax, the number of population has an affect on the realization of property tax, the area has an effect on property tax, the building area has an effect on realization of property tax and the gross regional domestic product has no effect on realization of property tax.
\end{abstract}

Keywords: Number of Taxpayers, Population, Area, Building area, Gross Regional Domestic Product, Property Tax.

\begin{abstract}
Abstrak: Tujuan penelitian adalah untuk menguji pengaruh dari jumlah wajib pajak, jumlah penduduk, luas wilayah, luas bangunan dan produk domestik regional bruto terhadap Realisasi Penerimaan Pajak Bumi dan Bangunan di Kabupaten Bangka Tengah. Obyek dari penelitian ini adalah penerimaan pajak bumi dan bangunan yang diterima oleh pemerintah Daerah Kabupaten Bangka Tengah. Populasi dalam penelitian ini adalah seluruh Desa/Kelurahan yang ada di Kabupaten Bangka Tengah yaitu 67 Desa/Kelurahan. Sampel yang diambil dalam penelitian ini sebanyak 250 sampel yang diperoleh dari 50 Desa/Kelurahan dari tahun 2010 sampai dengan tahun 2014. Data yang digunakan dalam penelitian ini adalah data sekunder. Hasil dari penelitian ini adalah bahwa jumlah wajib pajak berpengaruh terhadap Realisasi Penerimaan Pajak Bumi dan Banguna, jumlah penduduk berpengaruh terhadap Realisasi Penerimaan Pajak Bumi dan Bangunan, luas wilayah berpengaruh terhadap Realisasi Penerimaan Pajak Bumi dan Bangunan, luas bangunan berpengaruh terhadap Realisasi Penerimaan Pajak Bumi dan Bangunan, dan produk domestik regional bruto tidak berpengaruh terhadap Realisasi Penerimaan Pajak Bumi dan Bangunan.
\end{abstract}

Kata Kunci: Jumlah Wajib Pajak, Jumlah Penduduk, Luas Wilayah, Luas Bangunan, Produk Domestik Regional Bruto, Realisasi Penerimaan Pajak Bumi dan Bangunan. 


\section{PENDAHULUAN}

Pajak merupakan salah satu sumber utama pendapatan pemerintah baik di daerah maupun pusat, pemungutannya dilakukan oleh pemerintah serta dapat dipaksakan, kemudian penerimaan pajak tersebut digunakan untuk melaksanakan pembangunan yang bertujuan untuk meningkatkan kesejahteraan masyarakat. Peran pajak dalam sistem pembangunan di Indonesia sangatlah penting karena penerimaan negara sangat bergantung pada pembayaran pajak yang dilakukan oleh masyarakat baik orang pribadi maupun badan atas penghasilan yang diterimanya.

Sistem perpajakan yang digunakan di Indonesia adalah sistem self assessment system yang memungkinkan masyarakat untuk menghitung sendiri besarnya jumlah pajak yang harus dibayar, melakukan penyetoran pajak sendiri dan melaporkan pajak yang sudah disetor kepada Kantor Pelayanan Pajak dalam bentuk Surat Pemberitahuan (SPT) sesuai dengan ketentuan yang berlaku, sehingga memudahkan masyarakat dalam membayar pajak dan diharapakan dapat meningkatkan penerimaan pajak negara terutama pajak bumi dan bangunan di sektor perkotaan dan pedesaan, sehingga penerimaan pendapatan daerah dapat dioptimalkan dan pembangunan daerah dapat terus berjalan.

Pajak bumi dan bangunan sebelumnya merupakan pajak pusat yang dikelola oleh pemerintah pusat yang dipungut melalui Direktorat Jendral Pajak yang sebagian besar hasilnya akan diserahkan ke pemerintah daerah yang selanjutnya akan digunakan untuk pembangunan daerah, namun pajak bumi dan bangunan sekarang sudah ditetapkan sebagai pajak daerah yang dipungut oleh pemerintah daerah berdasarkan Undang-undang Nomor 28 Tahun 2009 dan diatur oleh pemerintah daerah sejak tanggal 1 Januari 2014 dan pajak bumi dan bangunan menggunakan sistem pemungutan official assessment system dimana jumlah pajak terutang yang harus dibayar ditentukan oleh pemerintah atau petugas pajak, sehingga wajib pajak tidak perlu menghitung jumlah pajak yang harus dibayar.

Tujuan penelitian ini adalah untuk meng-uji pengaruh dari jumlah wajib pajak, jumlah penduduk, luas wilayah, luas bangunan dan produk domestik regional bruto terhadap Realisasi Penerimaan Pajak Bumi dan Bangunan sektor pedesaan dan perkotaan di Kabupaten Bangka Tengah tahun 2012-2014.

Penelitian ini disusun dengan sistematika penulisan yang pertama yaitu pendahuluan, menjelaskan mengenai latar belakang penelitian, masalah penelitian, tujuan penelitian, manfaat penelitian, dan sistematika penelitian. Kedua yaitu kerangka teoritis dan pengembangan hipotesis yang menguraikan landasan dan pengertian mengenai pajak bumi dan bangunan. Ketiga metoda penelitian yang terdiri dari bentuk penelitian, obyek penelitian, definisi dan pengukuran variabel, teknik penumpulan data, metoda analisis data. Keempat yaitu mengenai analisis dan pembahasan berupa hasil penelitian dan hasil pengujian. Dan kelima yaitu penutup yang berisi kesimpulan, keterbatasan dan rekomendasi.

\section{KERANGKA TEORITIS}

\section{Pengertian Pajak Bumi dan Bangunan}

Bumi adalah permukaan bumi dan tubuh bumi yang ada dibawahnya. Sedangkan bangunan adalah konstruksi teknis yang ditanam atau dilekatkan secara tetap pada tanah dan/ atau perairan, jadi pajak bumi dan bangunan pedesaan dan perkotaan adalah pajak atas bumi dan atau bangunan yang dimiliki, dikuasai, dan atau dimanfaatkan oleh orang pribadi atau badan, kecuali kawasan yang digunakan untuk kegiatan usaha perkebunan, perhutanan, dan pertambangan.

\section{Subyek Pajak dan Wajib Pajak}

Subyek pajak Bumi dan Bangunan sektor perkotaan dan perdesaan adalah orang pribadi atau badan yang secara nyata mempunyai suatu hak atas bumi dan atau memperoleh manfaat atas bumi, dan atau memiliki, menguasai, 
dan atau memperoleh manfaat atas bangunan. Subjek pajak yang dikenakan kewajiban untuk membayar pajak disebut juga Wajib Pajak, dan apabila suatu objek pajak belum jelas wajib pajaknya, maka Kepala Dinas Pelayanan Pajak atas nama Gubernur dapat menetapkan subjek pajak sebagai Wajib Pajak.

Wajib pajak adalah orang pribadi atau badan yang meliputi pembayar pajak, pemotong pajak dan pemungut pajak yang mempunyai hak dan kewajiban perpajakan sesuai dengan ketentuan dan juga peraturan perundang-undangan perpajakan daerah yang berlaku di daerah tersebut.

\section{Obyek Pajak dan Bukan Obyek Pajak}

Obyek dari Pajak Bumi dan Bangunan sektor perdesaan dan perkotaan adalah bumi dan atau bangunan yang dimiliki, dikuasai, dan atau dimanfaatkan oleh orang pribadi atau badan, kecuali kawasan yang digunakan untuk usaha perkebunan, perhutanan, dan pertambangan.

Dalam pengenaan Pajak Bumi dan Bangunan sektor pedesaan dan perkotaan, yang termasuk dalam pengertian bangunan yang menjadi objek pajak adalah sebagai berikut:

1. Jalan lingkungan yang terletak dalam suatu kompleks bangunan seperti hotel, pabrik, dan emplasemennya, yang merupakan suatu kesatuan dengan kompleks bangunan tersebut.

2. Jalan tol.

3. Kolam renang.

4. Pagar mewah.

5. Tempat olahraga.

6. Galangan kapal, dermaga.

7. Taman mewah.

8. Tempat penampungan/kilang minyak, air dan gas, pipa minyak.

9. Menara.

Sedangkan objek pajak yang tidak dikenakan Pajak Bumi dan Bangunan, yaitu:

1. Digunakan oleh Pemerintah dan Daerah untuk penyelenggaraan pemerintahan.
2. Digunakan semata-mata untuk melayani kepentingan umum di bidang ibadah, sosial, kesehatan, pendidikan, dan kebudayaan nasional, yang tidak dimaksudkan untuk memperoleh keuntungan.

3. Digunakan untuk kuburan, peninggalan purbakala, dan sejenisnya.

4. Merupakan cagar budaya yang tidak dimanfaatkan sebagai tempat hunian atau tempat tinggal, dan kegiatan usaha atau sejenisnya, tidak dimaksudkan untuk memperoleh keuntungan.

5. Merupakan ruang terbuka hijau (kawasan hijau lindung dan hijau binaan), hutan lindung, hutan suaka alam, hutan wisata, taman nasional, dan tanah negara yang belum dibebani suatu hak.

6. Digunakan oleh badan perwakilan diplomatik dan konsulat berdasarkan asas perlakuan timbal balik.

7. Digunakan oleh badan atau perwakilan lembaga internasional yang ditetapkan dengan Peraturan Menteri Keuangan.

\section{Dasar Pengenaan Pajak}

Dasar Pengenaan Pajak Bumi dan Bangunan sektor pedesaan dan perkotaan adalah Nilai Jual Objek Pajak, dimana Nilai Jual Objek Pajak itu sendiri adalah harga rata-rata yang diperoleh dari transaksi jual beli yang terjadi secara wajar, dan bilamana tidak terdapat transaksi jual beli maka Nilai Jual Objek Pajak ditentukan melalui perbandingan harga dengan objek lain yang sejenis, atau nilai perolehan baru, atau Nilai Jual Objek Pajak pengganti.

\section{Tarif Pajak Bumi dan Bangunan di Kabupaten Bangka Tengah.}

Tarif pajak Bumi dan Bangunan Pedesaan dan Perkotaan di Kabupaten Bangka Tengah adalah sebagai berikut:

\begin{tabular}{cc}
\hline NJOP & Tarif \\
\hline Sampai dengan 1.000.000.000 & $0,1 \%$ \\
$>1.000 .000 .000$ & $0,2 \%$ \\
\hline
\end{tabular}




\section{Tata Cara Perhitungan Pajak Bumi dan Bangunan}

Besarnya pokok Pajak Bumi dan Bangunan untuk sektor Pedesaan dan perkotaan terutang dapat dihitung dengan cara:

PBB terutang $=$ Tarif Pajak $\times($ NJOP - NJOPTKP $)$

Besarnya NJOPTKP ditetapkan oleh peraturan daerah masing-masing dengan ketentuan minimal Rp 10.000.000,00 (sepuluh juta rupiah). Berdasarkan Perda No. 30 Tahun 2011 besarnya NJOPTKP di Bangka Tengah adalah Rp 10.000.000,00 (sepuluh juta rupiah) untuk setiap wajib pajak.

\section{METODA PENELITIAN}

\section{Bentuk Penelitian}

Penelitian ini menggunakan pendekatan kuantitatif dengan bentuk penelitian kausalitas. Penelitian kausalitas adalah penelitian yang menguji pengaruh atau sebab akibat antar variabel independen dan variabel dependen dengan menggunakan alat analisa regresi berganda.

\section{Obyek Penelitian}

Objek dalam penelitian ini adalah realisasi penerimaan Pajak Bumi dan Bangunan sektor pedesaan dan perkotaan di Kabupaten Bangka Tengah, dan populasi dalam penelitian ini adalah seluruh Desa/Kelurahan di Kabupaten Bangka Tengah sehingga terdapat 67 Desal Kelurahan yang dijadikan sebagai populasi, dan yang menjadi sampel dalam penelitian ini adalah 50 Desa/Kelurahan dengan jangka waktu penelitian selama 5 tahun yaitu dari tahun 2010 sampai tahun 2014 sehingga total sampel sebanyak 250 sampel.

Teknik sampling yang digunakan oleh peneliti adalah nonprobability sampling yang merupakan teknik yang tidak memberikan peluang atau kesempatan yang sama bagi setiap elemen dalam populasi untuk menjadi sampel. Jenis teknik non probability sampling yang digunakan dalam penelitian ini adalah nonprobability convenience sampling, dimana sampel yang diambil tidak secara acak, sehingga memungkinkan peneliti untuk memilih sampel yang memudahkan akses peneliti untuk pengambilan data.

\section{Definisi Variabel dan Pengukuran}

\section{Jumlah Wajib Pajak}

Wajib Pajak adalah orang pribadi atau badan, meliputi pembayar pajak, pemotong pajak, dan pemungut pajak, yang mempunyai hak dan kewajiban perpajakan sesuai dengan ketentuan peraturan perundang-undangan perpajakan. Wajib Pajak untuk Pajak Bumi dan Bangunan dibedakan menjadi 2 (dua) yaitu wajib pajak sektor perkotaan dan Wajib Pajak sektor pedesaan.

Jumlah wajib pajak (X1) diukur menggunakan satuan jumlah orang yang memiliki obyek dari pajak bumi dan bangunan itu sendiri atau orang yang menguasai dan memperoleh manfaat atas bumi dan bangunan pada tahun 2010-2014.

\section{Jumlah Penduduk}

Penduduk adalah semua orang yang mendiami wilayah suatu negara dalam kurun waktu tertentu. Pertumbuhan penduduk merupakan salah satu unsur penting yang dapat memacu pertumbuhan ekonomi suatu wilayah, dengan pertumbuhan dan jumlah penduduk yang tinggi maka akan dapat menggerakkan kegiatan ekonomi suatu daerah.

Jumlah wajib penduduk (X2) diukur menggunakan satuan orang/jiwa yang berada di Kabupaten Bangka Tengah yang terdiri dari beberapa Desa/Kelurahan yang terdaftar pada Badan Pusat Statistik Provinsi Kepulauan Bangka Belitung selama tahun 2010-2014.

\section{Jumlah Luas Wilayah}

Bumi adalah permukaan bumi dan tubuh bumi yang ada dibawahnya. Berdasarkan definisi diatas permukaan bumi dapat dikatakan 
sebagai tanah yang tidak lain merupakan objek dari Pajak Bumi dan Bangunan serta bangunan itu sendiri yang berada diatasnya.

Jumlah luas wilayah (X3) diukur menggunakan luas wilayah yang terdaftar disetiap Desa/Kelurahan yang ada di Kabupaten Bangka Tengah selama tahun 2010-2014. Luas wilayah diwakili oleh luas bumi dalam data penelitian.

\section{Jumlah Luas Bangunan}

Bangunan adalah konstruksi teknik yang ditanam atau dilekatkan secara tetap pada tanah dan/atau perairan.

Luas bangunan (X4) diukur menggunakan satuan $\mathrm{m}^{2}$ sesuai dengan jumlah luas bangunan yang ada di Kabupaten Bangka Tengah yang sudah terdaftar yang dibagi menjadi luas bangunan per Desa/kelurahan selama tahun 20102014.

\section{Produk Domestik Regional Bruto}

Produk Domestik Regional Bruto (PDRB) merupakan salah satu indikator makro keberhasilan suatu pembangunan ekonomi suatu daerah serta untuk mengetahui tingkat dan pertumbuhan pendapatan masyarakat untuk melihat gambaran secara menyeluruh tentang kondisi perekonomian suatu wilayah.

Manfaat yang dapat diperoleh dari data Produk Domestik Regional Bruto ini adalah sebagai berikut:

1. PDRB atas harga berlaku (nominal) digunakan untuk mengetahui kemampuan sumber daya ekonomi, pergeseran, dan struktur ekonomi suatu daerah.

2. PDRB atas dasar harga konstan (rill) dapat digunakan untuk menunjukkan laju pertumbuhan ekonomi secara keseluruhan dari tahun ke tahun yang menggambarkan perkembangan produksi rill barang dan jasa yang dihasilkan dearah tersebut.

Produk Domestik Regional Bruto (X5) diukur berdasarkan harga konstan yang terjadi dalam suatu perekonomian dalam satuan rupiah selama tahun 2010-2014.

\section{Realisasi Penerimaan Pajak Bumi dan Bangunan Perdesaan dan Perkotaan}

Setelah ditetapkannya Pajak Bumi dan Bangunan sebagai salah satu dari pajak daerah sesuai dengan Undang-undang No.28 tahun 2009 yang pelaksanaannya dilimpahkan ke pemerintah daerah dan menjadi sumber pemasukan pendapatan daerah, maka pemerintah daerah harus dapat mengoptimalkan penerimaan daerahnya, khususnya penerimaan pajak dari Pajak Bumi dan Bangunan Sektor Pedesaan dan Perkotaan dengan mengoptimalkan objek pajak yang ada di daerah tersebut khususnya di daerah Bangka Tengah.

Selain itu penerimaan pajak terutama Pajak Bumi dan Bangunan juga dapat dilakukan dengan memberikan fasilitas yang memadai yang dapat memberikan kemudahan bagi masyarakat untuk membayar pajak, sehingga penerimaan Pajak Daerah dapat berimplikasi pada kemajuan dalam pembangunan daerah itu sendiri.

Penerimaan pajak bumi dan bangunan $(Y)$ diukur dengan menggunakan jumlah peneri-maan pajak bumi dan bangunan di setiap Desal Kelurahan dalam satuan rupiah selama tahun 2010-2014 di Kabupaten Bangka Tengah.

\section{Teknik Pengumpulan Data}

Jenis data yang digunakan dalam penelitian ini adalah data sekunder. Data Sekunder adalah data yang diperoleh atau dikumpulkan peneliti dari berbagai sumber yang telah ada.

Metode pengumpulan data yang digunakan dalam penelitian ini adalah metode dokumentasi dan studi pustaka. Metode dokumentasi adalah suatu metode yang diperoleh dengan cara melihat dan mengumpulkan dokumendokumen serta laporan-laporan yang berkaitan dengan penelitian yang sedang diteliti sedangkan studi pustaka adalah pengumpulan data yang dilakukan dengan cara membaca literatur yang ada hubungannya dengan penelitian ini untuk memperoleh pemahaman mengenai variabel- 
variabel yang digunakan melalui jurnal-jurnal maupun buku-buku yang terkait dengan penelitian ini.

\section{Metode Analisis Data}

Data yang telah dikumpulkan melalui berbagai sumber kemudian akan diolah untuk mendapatkan hasil yang kemudian akan digunakan untuk membuktikan hipotesis-hipotesis yang sudah dibentuk dan selanjutnya akan diuji dengan menggunakan Model Regresi Berganda.

\section{HASIL PENELITIAN}

Statistik deskriptif memberikan gambaran data yang dilihat dari nilai rata-rata, standar deviasi, minimum dan maksimum. Hasil pengolahan statistik deskriptif adalah sebagai berikut:

Tabel 1 Hasil Statistik Deskriptif Sebelum Uji Outlier

\begin{tabular}{crrrrr}
\hline Variabel & N & Minimum & Maksimum & \multicolumn{1}{c}{ Mean } & \multicolumn{1}{c}{ Std.Deviasi } \\
\hline X1 & 250 & 229 & 2.130 & 650,86 & 337,528 \\
X2 & 250 & 856 & 7.159 & $3.004,76$ & $1.437,392$ \\
X3 & 250 & 71.085 & 5.267 .114 & $1.476 .155,36$ & $1.272 .904,519$ \\
X4 & 250 & 9.088 & 285.104 & $30.781,30$ & $36.791,204$ \\
X5 & 250 & 4.502 .396 & 5.303 .106 & $4.963 .087,60$ & $295.362,405$ \\
Y & 250 & 106.460 & 1.967 .570 .056 & $45.480 .120,56$ & $205.756 .945,623$ \\
\hline
\end{tabular}

Sumber : Hasil data pengolahan SPSS Versi 19

Tabel 2 Hasil Statistik Deskriptif Setelah Uji Outlier

\begin{tabular}{ccrrrr}
\hline Variabel & N & Minimum & Maksimum & \multicolumn{1}{c}{ Mean } & \multicolumn{1}{c}{ Std.Deviasi } \\
\hline X1 & 247 & 229 & 1.794 & 635,86 & 309,893 \\
X2 & 247 & 856 & 6.817 & $2.957,27$ & $1.378,878$ \\
X3 & 247 & 71.085 & 4.938 .604 & $1.447 .413,98$ & $1.239 .471,684$ \\
X4 & 247 & 9.088 & 255.330 & $28.194,86$ & $28.079,447$ \\
X5 & 247 & 4.502 .396 & 5.303 .106 & $4.959 .278,35$ & $295.079,207$ \\
Y & 247 & 106.460 & 1.388 .211 .024 & $30.928 .530,98$ & $134.509 .698,945$ \\
\hline
\end{tabular}

Sumber : Hasil data pengolahan SPSS Versi 19

Untuk mengetahui pengaruh antara variabel independen jumlah wajib pajak, jumlah penduduk, jumlah luas wilayah, jumlah luas bangunan, PDRB secara individual terhadap penerimaan PBB P2 maka dilakukan uji t,berikut adalah tabel hasil uji t: 
Tabel 3 Hasil Uji t

\begin{tabular}{|c|c|c|c|c|}
\hline \multirow{2}{*}{ Model } & \multicolumn{2}{|c|}{ Unstandardized Coefficients } & \multirow{2}{*}{$\mathrm{t}$} & \multirow{2}{*}{ Sig. } \\
\hline & B & Std. Error & & \\
\hline $\mathrm{X} 1$ & $-205218,172$ & 21851,444 & $-9,392$ & 0,000 \\
\hline $\mathrm{X} 2$ & $-12359,121$ & 3347,431 & $-3,692$ & 0,000 \\
\hline $\begin{array}{l}X 3 \\
X 4\end{array}$ & 38,568 & 3,666 & 10,521 & 0,000 \\
\hline \multirow[t]{2}{*}{$x 5$} & 5515,035 & 149,880 & 36,796 & 0,000 \\
\hline & 5,209 & 10,492 & ,496 & 0,620 \\
\hline
\end{tabular}

Sumber : Hasil pengolahan data SPSS Versi 19

Berdasarkan tabel 3 diketahui bahwa nilai Sig variabel jumlah wajib pajak (X1) adalah sebesar 0,000 yang lebih kecil dari nilai alpha $(a=0,05)$, sehingga dapat disimpulkan bahwa $\mathrm{Ha}$ diterima dan hal ini berarti jumlah wajib pajak (X1) berpengaruh terhadap realisasi penerimaan pajak bumi dan bangunan sektor pedesaan dan perkotaan di kabupaten Bangka Tengah. Hal ini sejalan dengan penelitian Sasana (2005) yang menunjukkan bahwa jumlah wajib pajak berpengaruh terhadap penerimaan pajak bumi dan bangunan.

Untuk variabel jumlah wajib pajak menunjukkan nilai koefisien regresi sebesar 205.218,172 hal ini berarti bahwa untuk setiap kenaikan satu jumlah wajib pajak (X1) di setiap desa/kelurahan di Bangka Tengah akan menurunkan realisasi penerimaan PBB $(Y)$ sebesar 205.218,172.

Untuk mengukur seberapa besar jumlah wajib pajak yang terdaftar jika dibandingkan dengan jumlah penduduk yang ada pada suatu daerah menggunakan tax ratio, dengan pengukuran sebagai berikut:
Tabel 4 Tabel Tax Ratio

\begin{tabular}{cccc}
\hline & $\begin{array}{c}\text { Jumlah Wajib } \\
\text { Pajak }\end{array}$ & $\begin{array}{c}\text { Jumlah } \\
\text { Penduduk }\end{array}$ & Tax Ratio \\
\hline 2010 & 29.960 & 149.532 & $\mathbf{2 0 , 0 3 6 \%}$ \\
2011 & 30.188 & 149.858 & $\mathbf{2 0 , 1 4 4 \%}$ \\
2012 & 32.527 & 154.150 & $\mathbf{2 1 , 1 0 1 \%}$ \\
2013 & 31.262 & 140.365 & $\mathbf{2 2 , 2 7 2 \%}$ \\
2014 & 33.121 & 136.540 & $\mathbf{2 4 , 2 5 7 \%}$ \\
\hline
\end{tabular}

Sumber: DPPKAD Kabupaten Bangka Tengah, diolah sendiri.

$$
\text { Tax Ratio }=\frac{\text { Jumlah Wajib Pajak }}{\text { Jumlah Penduduk }}
$$

Berdasarkan tabel 3 diketahui bahwa nilai Sig variabel jumlah penduduk (X2) adalah sebesar 0,000 yang lebih kecil dari nilai alpha $(a=0,05)$, sehingga dapat disimpulkan bahwa $\mathrm{Ha}$ diterima dan hal ini berarti jumlah penduduk (X2) berpengaruh terhadap realisasi penerimaan pajak bumi dan bangunan sektor pedesaan dan perkotaan di kabupaten Bangka Tengah. Hal ini sejalan dengan penelitian dari Trigiant et al (2013) dan penelitian Hasanudin (2011) yang menunjukkan bahwa jumlah penduduk berpengaruh terhadap penerimaan pajak bumi dan bangunan. 
Untuk variabel jumlah penduduk (X2) menunjukkan koefisien regresi sebesar -12.359,121 hal ini menunjukkan bahwa setiap kenaikan satu jumlah penduduk di setiap desa/ kelurahan di Bangka Tengah (X2) akan mengurangi realisasi penerimaan PBB sebesar 12.359,12.

Berdasarkan tabel 3 diketahui bahwa nilai Sig variabel jumlah luas wilayah (X3) adalah sebesar 0,000 yang lebih kecil dari nilai alpha $(\alpha=0,05)$, sehingga dapat disimpulkan bahwa Ha diterima dan hal ini berarti jumlah luas wilayah (X3) berpengaruh terhadap realisasi penerimaan pajak bumi dan bangunan sektor pedesaan dan perkotaan di kabupaten Bangka Tengah. Hal ini sejalan dengan penelitian Sasana (2005) dan Tiara (2013) yang menunjukkan bahwa luas wilayah berpengaruh terhadap pene-rimaan pajak bumi dan bangunan.

Variabel jumlah luas wilayah (X3) menunjukkan koefisien regresi sebesar 38,568 , hal ini berarti bahwa setiap kenaikan satu meter persegi $\left(1 \mathrm{~m}^{2}\right)$ lahan di setiap desa/kelurahan di Bangka Tengah akan meningkatkan realisasi penerimaan PBB P2 sebesar 38,568.

Berdasarkan tabel 3 diketahui bahwa nilai Sig variabel jumlah luas bangunan (X4) adalah sebesar 0,000 yang lebih kecil dari nilai alpha $(\alpha=0,05)$, sehingga dapat disimpulkan bahwa Ha diterima dan hal ini berarti jumlah luas bangunan (X4) berpengaruh terhadap realisasi penerimaan pajak bumi dan bangunan sektor perdesaan dan perkotaan di kabupaten Bangka Tengah. Hal ini sejalan dengan penelitian dari Sasana (2005) dan penelitian Tiara (2013) yang menunjukkan bahwa luas bangunan berpengaruh terhadap penerimaan pajak bumi dan bangunan.

Variabel jumlah luas bangunan (X4) menunjukkan koefisien regresi sebesar 5.515,035, hal ini berarti bahwa setiap kenaikan satu meter persegi $\left(1 \mathrm{~m}^{2}\right)$ bangunan di setiap desa/kelurahan di Bangka Tengah akan meningkatkan realisasi penerimaan PBB sebesar 5.515,035.
Berdasarkan tabel 3 diketahui bahwa nilai Sig variabel PDRB (X5) adalah sebesar 0,620 dimana nilai tersebut lebih besar dari nilai alpha $(\alpha=0,05)$, sehingga dapat disimpulkan bahwa Ha tidak diterima dan hal ini berarti PDRB (X5) tidak berpengaruh terhadap realisasi penerimaan pajak bumi dan bangunan sektor pedesaan dan perkotaan di kabupaten Bangka Tengah.

Variabel independen yang terakhir yaitu PDRB (X5) yang diukur berdasarkan harga konstan menunjukkan nilai koefisien regresi sebesar 5,209, hal ini menunjukkan bahwa setiap kenaikan satu satuan rupiah PDRB akan meningkatkan realisasi penerimaan PBB P2 sebesar 5,209.

\section{PENUTUP}

Penelitian ini dilakukan untuk mendapatkan bukti empiris pengaruh jumlah wajib pajak, jumlah penduduk, luas wilayah, luas bangunan, dan produk domestik regional bruto terhadap penerimaan pajak bumi dan bangunan sektor perdesaan dan perkotaan. Hasil dari penelitian ini dapat disimpulkan sebagai berikut:

1. Variabel jumlah wajib pajak (X1) berpengaruh terhadap penerimaan pajak bumi dan bangunan sektor perdesaan dan perkotaan di Kabupaten Bangka Tengah, hal ini sejalan dengan penelitian Sasana (2005) yang menunjukkan jumlah wajib pajak memiliki pengaruh terhadap penerimaan pajak bumi dan bangunan.

2. Variabel jumlah penduduk (X2) berpengaruh terhadap penerimaan pajak bumi dan bangunan sektor perdesaan dan perkotaan di Kabupaten Bangka Tengah, hal ini sejalan dengan penelitian Trigiant et al (2013) dan Hasanudin (2011) yang menunjukkan bahwa jumlah penduduk berpengaruh terhadap penerimaan pajak bumi dan bangunan. 
3. Variabel luas wilayah (X3) berpengaruh terhadap penerimaan pajak bumi dan bangunan sektor perdesaan dan perkotaan di Kabupaten Bangka Tengah. Hal ini sejalan dengan penelitian Sasana (2005) dan Tiara (2013) yang menunjukkan bahwa luas wilayah berpengaruh terhadap penerimaan pajak bumi dan bangunan.

4. Variabel luas bangunan (X4) berpengaruh terhadap penerimaan pajak bumi dan bangunan sektor perdesaan dan perkotaan di Kabupaten Bangka Tengah. Hal ini sejalan dengan penelitian Sasana (2005) dan Tiara (2013) yang menunjukkan bahwa luas bangunan berpengaruh terhadap penerimaan pajak bumi dan bangunan.

5. Variabel produk domestik regional bruto (X5) tidak berpengaruh terhadap penerimaan pajak bumi dan bangunan sektor perdesaan dan perkotaan di Kabupaten Bangka Tengah. Hal ini tidak sejalan dengan penelitian Sasana (2005) dan Hasanudin (2011) yang menyatakan bahwa produk domestik regional bruto berpengaruh terhadap penerimaan pajak bumi dan bangunan.

Penelitian ini memiliki beberapa keterbatasan, berikut adalah keterbatasan dalam penelitian ini:
1. Data yang digunakan mengalami masalah heteroskedastisitas pada variabel luas wilayah.

2. Ruang lingkup penelitian hanya sebatas di Kabupaten Bangka Tengah, karena peneliti hanya bisa mendapatkan data di Kabupaten Bangka Tengah saja.

3. Periode penelitian yang relatif singkat selama 5 tahun yaitu tahun 2010, 2011, 2012, 2013, 2014.

4. Data Produk Domestik Regional Bruto yang di dapatkan oleh peneliti hanya berdasarkan data per Kabupaten bukan per Desa/Kelurahan.

Bagi peneliti selanjutnya yang akan mengambil topik yang sejenis berikut ini terdapat beberapa rekomendasi agar penelitian selanjutnya dapat lebih baik, yaitu:

1. Agar peneliti selanjutnya dapat menghilangkan masalah heteroskedastisitas yang terjadi.

2. Agar peneliti selanjutnya dapat memperluas obyek penelitian, tidak hanya di Kabupaten Bangka Tengah saja tapi di daerah lainnya.

3. Agar peneliti selanjutnya dapat melakukan penelitian dengan periode penelitian yang lebih panjang agar hasil penelitian yang dilakukan dapat lebih baik.

4. Agar peneliti selanjutnya yang menggunakan variabel PDRB dapat mendapatkan data PDRB yang lebih rinci per wilayahnya.

\section{REFERENSI:}

Ghozali, Imam. 2013. Aplikasi Analisis Multivariate dengan Program IBM SPSS 21 Update PLS Regresi. Semarang: Badan Penerbit Universitas Diponegoro.

Hasanudin, Mohamad. 2011. Analisis Pengaruh Jumlah Penduduk, Produk Domestik Regional Bruto (PDRB), dan Tingkat Inflasi Terhadap Penerimaan Pajak Bumi dan Bangunan (PBB) di Kabupaten Kendal, Demak, Kudus dan Kota Semarang Tahun 2001-2008. Teknis, Vol. 6, No. 1: 24-30.

Lesmana, Eko J. 2014. Undang-Undang Pajak Lengkap Tahun 2014. Jakarta: Mitra Wacana Media.

Makmur. 2010. Faktor-Faktor yang Mempengaruhi Penerimaan PBB-Pajak Bumi dan Bangunan-di Kabupaten Kutai Barat. Jurnal Eksis, Vol. 6 No. 2: 1440-1605.

Morissan, Andy Corry., Farid Hamid. 2012. Metode Penelitian Survey. Jakarta: Prenada Media.

Prawoto, Agus. 2011. Penilaian Pajak Bumi dan Bangunan Perdesaan \& Perkotaan. Yogyakarta: BPFE Yogyakarta. Priantara, Diaz. 2013. Perpajakan Indonesia, Edisi 2 Revisi. Jakarta: Mitra Wacana Media.

Santoso, Singgih. 2012. Aplikasi SPSS pada Statistik Parametrik. Jakarta: Elek Media Komputindo. 
Sasana, Hadi. 2005. Analisis Faktor-Faktor yang Mempengaruhi Penerimaan Pajak Bumi dan Bangunan (PBB) Studi Kasus di Kabupaten Banyumas. Dinamika Pembangunan, Vol. 2 No. 1: 19-29.

Siahaan, Marihot Pahala. 2010. Pajak Daerah \& Retribusi Daerah. Jakarta: Rajawali Pers.

Susanto, Paojan Mas'ud. 2014. Perpajakan Indonesia (Teori dan Aplikasi). Jakarta: Mitra Wacana Media.

Tiara, Shita. 2013. Analisis Atribut-Atribut yang Mempengaruhi Penerimaan Pajak Bumi dan Bangunan (PBB) Terhadap Pendapatan Daerah di Kota Medan.

Tim Redaksi. 2009. Undang-Undang Pajak Daerah dan Retribusi Daerah. Jakarta: Fokus Media.

Trigiant, Jefry., Dandes Rifa, Ethika. 2013. Kajian Empiris Tentang Faktor-Faktor yang Mempengaruhi Penerimaan Pajak Bumi dan Bangunan (PBB) di Kota Padang.

Waluyo. 2010. Perpajakan Indonesia, Edisi 9 Buku 2. Jakarta: Penerbit Salemba Empat.

http://blogpki.blogspot.com/2013/05/teori-dan-pengertian-kependudukan.html

http://litamardiana.blogspot.com/2012/11/pengertan-penduduk-di-indonesia.html

http://www.tarif.depkeu.go.id/Bidang/?bid=pajak\&cat=pbb

http://www.bangkatengahkab.go.id/index.php?option=com content\&view=article\&id=1381pak-erzaldi-target-pbbbateng-rp-7-miliar\&catidnewsflash\&ltemid=182 